\title{
Pull-Out Work of Steel Fibers From Cementitious Composites: Analytical Investigation
}

\author{
J. M. Alwan, A. E. Naaman \& W. Hansen \\ Department of Civil Engineering, 2340 G.G. Brown Building, College of Engineering, University of Michigan, Ann \\ Arbor, MI 48109-2125, USA
}

(Received 7 January 1991; accepted 24 May 1991)

\begin{abstract}
The main objective of this study is to provide a parametric evaluation of the pull-out work of smooth steel fibers embedded in cementitious matrices. The various parameters controlling the behavior of the bond stress versus slip relationship are analyzed; their effects on the entire pull-out load versus slip response and the corresponding pull-out energy up to full debonding and/or up to total pull-out are investigated. Also discussed are the effects of the fiber geometric parameters such as fiber diameter, length, and aspect ratio. Finally, a brief section addresses the relation between pullout work and the critical strain energy release rate $G_{\mathrm{c}}$, a fracture mechanics variable, which can be calculated if the $P-\Delta$ curve is known.
\end{abstract}

Keywords: Bond, bond-slip, cementitious, cracks, endslip, fiber reinforced concrete, interface, matrix, pullout work, debonding, shear stress, slip, steel fibers.

\section{INTRODUCTION}

It is generally agreed that the pull-out work of fibers bridging one or several cracks provides the main source of toughness or energy absorption capacity of fiber reinforced cement composites. ${ }^{1,4}$ The energy absorption capability of a composite is attributed to two basic mechanisms - material deformation and the formation of new surfaces by cracking. The material deformation occurs first. If the energy supplied is large enough, a crack may initiate and propagate, thus actuating the second energy-absorbing mechanism. Brittle materials, such as cementitious and ceramic matrices, exhibit low energy absorption or toughness as a result of the small amount of deformation they can sustain, and their poor resistance to cracking. Thus the total energy absorption capability of a material can be enhanced either by increasing the path of the cracks during separation or by increasing the material's capability to deform. These mechanisms can be achieved by addition of fibers. Fibers bridging a crack can absorb energy by deforming and/or pulling out, depending on their bond characteristics. ${ }^{3,6,7,13,15}$ The pull-out process involves, first, a debonding action which provides an alternative path for the crack to follow, and, second, the formation of a new surface at the fiber-matrix interface. ${ }^{12}$ Moreover, the fiber deformation and compliance during pull-out contributes directly to the total deformation of the composite. Thus, to design composites with high toughness, there is need to understand better the pull-out process and the energy absorbing mechanisms it generates.

To the authors' knowledge, only approximate simplified methods have been used so far to calculate the energy due to the debonding of fibers along the fiber-matrix interface, as well as to the kinematic pull-out of the fibers from the matrix. ${ }^{2,5,11}$ Moreover, the effect of the interfacial bond strength on the pull-out energy in the debonding stage, and the effect of frictional decay in the kinematic pull-out stage have not yet been thoroughly investigated.

\section{OBJECTIVE}

The main objective of this study is to provide a parametric evaluation of the pull-out work of smooth steel fibers embedded in cementitious matrices. The analytical model used to predict the pull-out load versus slip relationship ( $P-\Delta$ curve) of a fiber has been described in detail in previous

Cement \& Concrete Composites 0958-9465/92/\$5.00 @ 1992 Elsevier Science Publishers Ltd, England. Printed in Great Britain 
investigations..$^{8-10}$ The model is based on a given bond stress versus slip relationship ( $\tau-S$ curve) which can be either assumed or derived from experimental tests such as in Ref. 5.

The various parameters controlling the behavior of the bond stress versus slip relationship are analyzed; their effects on the entire pull-out load versus slip response and the corresponding pull-out energy up to full debonding and/or up to total pull-out are investigated. Also discussed are the effects of the fiber geometric parameters such as fiber diameter, length, and aspect ratio. Finally, a brief section considers the relation between pull-out work and the strain energy release rate $G$, a fracture mechanics variable, which can be calculated if the $P-\Delta$ curve is known.

\section{BACKGROUND OF THE ANALYTICAL MODEL}

The problem to be analyzed refers to a pull-out test whereby a tensile load $P$ is applied to the tip of a fiber embedded over a length $l$ in a cementitious body (Fig. 1), and where $\Delta$ denotes the displacement of the fiber relative to the penetration surface between the fiber and the matrix. Figure 1 shows three typical cases, namely, a fiber still under full elastic bonding, a fiber partially debonded, and a fiber in the process of being kinematically pulled out. A typical pull-out load versus end slip $(P-\Delta)$ curve is shown in Fig. 2, where the slip is plotted on a relatively small scale.
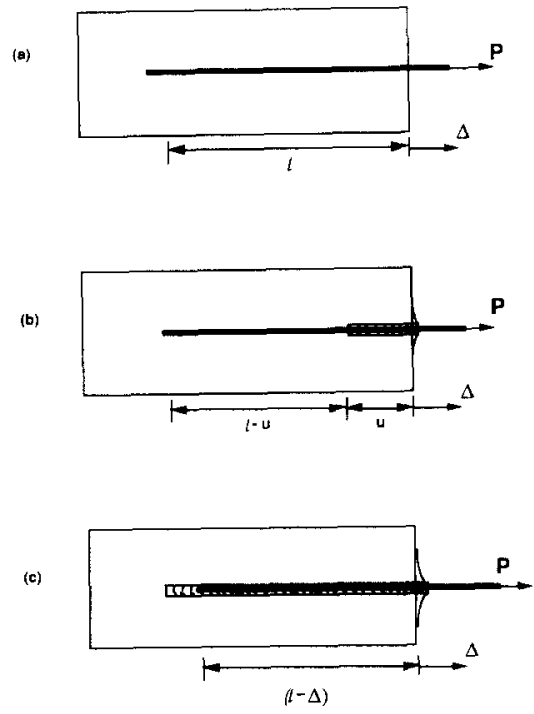

Fig. 1. Pull-out mechanism considered. (a) Pre-critical load; (b) partial debonding; (c) full debonding and dynamic pull-out.
Typical actual curves are shown in Fig. 3 for various parameters and up to large values of slip. As explained in Ref. 9, the $P-\Delta$ curve can be used to derive a bond stress versus slip $(\tau-S)$ curve. For a given matrix and fiber, the $\tau-S$ curve can be considered a constitutive property of the interface.

Typical relationships between the bond shear stress and the relative slip at the fiber-matrix interface as assumed in Ref. 9 are shown in Fig. 4. It is assumed that $\tau_{\mathrm{fi}}$, the initial frictional shear stress, is either equal to or smaller than the maximum stress, $\tau_{\max }$. The initial portion of the curve is assumed linear elastic up to $\tau_{\max }$, defined as the bond strength of the interface. However, beyond the peak stress, purely ideal frictional conditions are shown for one case with a frictional shear stress assumed to remain constant for any slip. In a second case, the frictional shear stress is shown to deteriorate and decrease as the slip between the fiber and the matrix increases. Such a phenomenon is probably due to the crumbling of the cement matrix in the fiber duct as the fiber is being pulled out. The crumbled particles provide a roller effect between the fiber and its duct, leading to a decrease in frictional stresses. Such a bond-slip relationship curve can be obtained

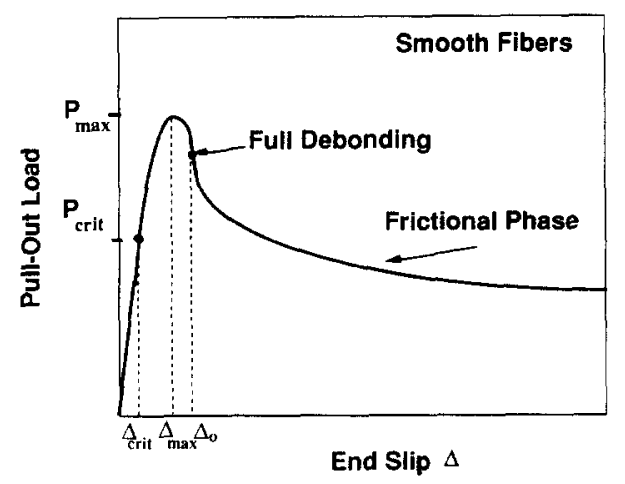

Fig. 2. Typical pull-out load versus slip relationship of smooth steel fibers in cement composites.

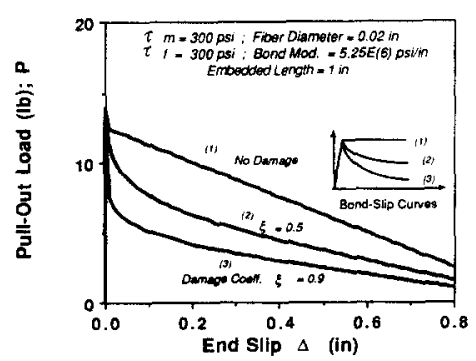

Fig. 3. Typical effect of decaying friction on the descending branch of the pull-out curve $(1 \mathrm{lb}=4.448 \mathrm{~N}, 1 \mathrm{in}=25.4 \mathrm{~mm}$, $1000 \mathrm{psi}=6.895 \mathrm{MPa}$ ). 

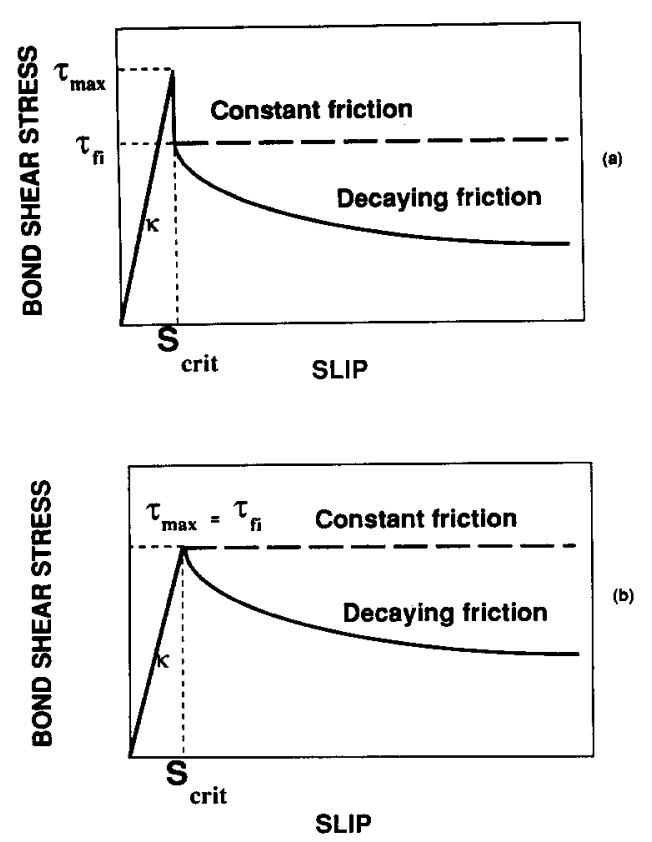

Fig. 4. Typical bond shear stress versus slip relationship. (a) $\tau_{\mathrm{fi}}<\tau_{\max } ;$ (b) $\tau_{\mathrm{fi}}=\tau_{\max }$.

from an experimental pull-out curve as shown in Fig. 5. The parameters defining the bond-slip curve (Figs 4 and 5) are:

$\tau_{\text {max }}$, maximum elastic bond shear stress;

$\tau_{\mathrm{fi}}$, initial frictional shear stress;

$\kappa$, bond modulus;

$\xi$, damage coefficient (or the rate at which the frictional shear stress deteriorates as a result of crumbled cement inside the fiber duct).

In most investigations to date, a constant frictional shear stress was assumed after full debonding. In this study, the pull-out energy will be computed for the case of a constant frictional shear stress as well as for that of a decaying frictional shear stress.

\section{DEFINITIONS AND ASSUMPTIONS}

The pull-out work is defined here as the work done by the pull-out load applied at the tip of the fiber as the fiber slips out of the matrix. It is assumed that the normal stress along the fiber does not exceed the yield or ultimate strength of the fiber material. This means that the fiber will not break, and that the pull-out work consists of two components, one needed to debond the fiber along the fiber-matrix interface and the other to pull out the fiber from the matrix.

From the above definition, the pull-out work can be calculated by integrating the pull-out load

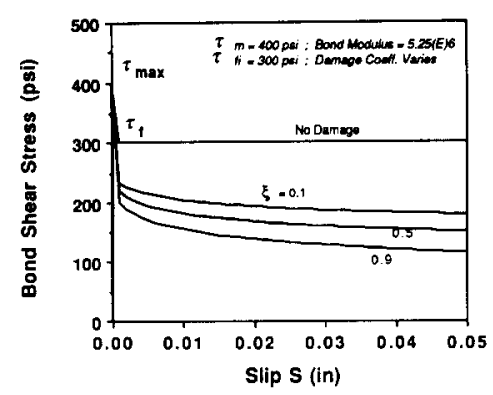

Fig. 5. Typical effect of damage coefficient $\xi$ on the bond-slip curve.

versus end displacement curve, that is, by computing the area under the curve. In this study, the numerical integration was carried using the trapezoidal rule with a relatively small step size to maximize accuracy.

\section{PREDICTED PULL-OUT CURVE}

For a given bond shear stress versus slip relationship curve of the type discussed in Figs 4 and 5 , a complete pull-out load versus slip curve (Fig. 3 ) can be predicted. The predicted pull-out curve is divided into three distinct regions:

(1) the pre-critical region, during which the fiber is assumed elastically bonded to the matrix;

(2) the partial debonding region, during which only a portion of the fiber is bonded and the behavior is primarily governed by the maximum elastic bond shear stress $\tau_{\max }$ and the initial frictional shear stress $\tau_{\mathrm{fi}}$;

(3) the pull-out region, during which the fiber is completely debonded and the kinematic mechanism of pull-out prevails; this region is controlled by frictional shear which could be assumed constant or decaying through the introduction of a suitable damage coefficient. It is important to mention that only in this stage can the deformation of the matrix be neglected, and the relative slip between the fiber and the matrix can be taken as approximately equal to the end displacement of the fiber.

\section{MATHEMATICAL EQUATIONS}

The mathematical derivation has been explained in detail in Ref. 9. The solution equations leading 
to the $P-\Delta$ curve (as in Fig. 3 ) are summarized below.

\section{Pre-critical and partial debonding regions}

For any value of $u$, the debonded length (Fig. 1(a), (b)), the pull-out load $P$ is obtained from

$$
\begin{aligned}
& P= \\
& \tau_{\mathrm{fi}} \psi u+\frac{\tau_{\max } \psi}{\lambda} \frac{1-\mathrm{e}^{-2 \lambda(1-u)}}{\frac{2}{Q} \mathrm{e}^{-\lambda(1-u)}+\left(1-\frac{1}{Q}\right)\left(1+\mathrm{e}^{-2 \lambda(l-u)}\right)}
\end{aligned}
$$

and the corresponding displacement $\Delta$ is given by

$$
\begin{aligned}
\Delta= & \left(P(Q-1) u-\frac{\tau_{\mathrm{fi}} \psi u^{2}}{2}(Q-2)+\left(P-\tau_{\mathrm{fi}} \psi u\right)\right. \\
& \left.\left(\frac{1-\mathrm{e}^{-\lambda(l-u)}}{1+\mathrm{e}^{-\lambda(l-u)}}\right) \frac{Q-2}{\lambda}-\tau_{\mathrm{fi}} \psi u l\right) / A_{\mathrm{m}} E_{\mathrm{m}}
\end{aligned}
$$

where $\Delta$ is the end displacement of the fiber, $u$ is the debonded length of the fiber, $Q=\left(A_{\mathrm{m}} E_{\mathrm{m}}+\right.$ $A_{\mathrm{f}} E_{\mathrm{f}} / / A_{\mathrm{m}} E_{\mathrm{m}}$

$$
\lambda=\sqrt{\frac{\psi \kappa}{A_{\mathrm{m}} E_{\mathrm{m}}}\left[1+\frac{A_{m} E_{\mathrm{m}}}{A_{\mathrm{f}} E_{\mathrm{f}}}\right]}
$$

in which $\psi$ is the fiber perimeter, $A_{\mathrm{m}}$ and $A_{\mathrm{f}}$ are the matrix and the fiber cross-sectional areas respectively, and $E_{\mathrm{m}}$ and $E_{\mathrm{f}}$ are the matrix and the fiber elastic moduli respectively.

\section{Pull-out region}

Once complete debonding has occurred at the fiber-matrix interface, Fig. 1(c), the pull-out load is given by

$$
P=\psi \tau_{\mathrm{fd}}(\Delta) .(l-\Delta)
$$

where $(l-\Delta)$ is the length of fiber remaining embedded for any slip $\Delta$ and $\tau_{\mathrm{fd}}(\Delta)$ is the frictional shear stress for a slip $\Delta$; the subscript 'd' implies damage or decay.

The frictional shear stress can be assumed constant for any slip $\Delta$. However, as, in real tests, it is shown to deteriorate with increasing slip, its value as derived in Ref. 5 is given by

$$
\begin{aligned}
\tau_{\mathrm{fd}}(\Delta)= & \tau_{\mathrm{fi}} \frac{\left.\exp \left[-\left(\Delta-\Delta_{0}\right)^{\eta}\right]-\xi \exp L-(l)^{\eta}\right]}{1-\xi \exp \left[-\left(l-\Delta+\Delta_{0}\right)^{\eta}\right]} \\
& \frac{\left(1-\exp \left(\frac{-2 v_{\mathrm{f}} \mu\left(l-\Delta+\Delta_{0}\right)}{E_{\mathrm{f}} r_{\mathrm{f}}\left(\frac{\left(1+v_{\mathrm{m}}\right)}{E_{\mathrm{m}}}+\frac{\left(1-v_{\mathrm{f}}\right)}{E_{\mathrm{f}}}\right)}\right)\right)}{\left(1-\exp \left(\frac{-2 v_{\mathrm{f}} \mu l}{E_{\mathrm{f}} r_{\mathrm{f}}\left(\frac{\left(1+v_{\mathrm{m}}\right)}{E_{\mathrm{m}}}+\frac{\left(1-v_{\mathrm{f}}\right)}{E_{\mathrm{f}}}\right)}\right)\right)}
\end{aligned}
$$

where $\Delta$ is the relative slip of the fiber after full debonding; $\Delta_{0}$ is the relative slip of the fiber at the end of full debonding (as a first approximation it can be taken as equal to the slip at maximum load; otherwise a more exact equation is given in Ref. $9) ; \xi$ is the damage coefficient, a dimensionless constant to give the analytical descending branch of the bond shear stress versus slip curve the same decaying trend as the experimental one; $\mu$ is the friction coefficient of the fiber-matrix interface; $v$ is Poisson's ratio, with subscript $f$ for fiber and $m$ for matrix; and $\eta$ is a coefficient describing the exponential shape of the descending branch of the bond shear stress versus slip curve; for smooth steel fibers a value of 0.2 is recommended in Ref. 9.

\section{PARAMETRIC EVALUATION OF PULL-OUT WORK}

The above mathematical model was used in a comprehensive parametric analysis of the pull-out load versus slip response of smooth steel fibers in a cementitious matrix with particular attention to the resulting pull-out work. The parameters studied included those influencing the bond-slip relationship and the fiber geometric parameters. Their effects are discussed below.

\section{Bond-slip parameters}

These parameters are $\tau_{\max }, \tau_{\mathrm{fi}}, \kappa$ and $\xi$; each affects the pull-out work in a particular way.

\section{Damage coefficient}

Figure 5 shows the influence of the damage coefficient $\xi$ on the bond-slip curve, ranging from a 'no damage case' or constant frictional bond 
stress, ${ }^{2,5,11}$ to a highly decaying frictional bond shear stress with a damage coefficient of 0.9 . The damage coefficient, $\xi$, is a dimensionless constant representing the amount of damage that occurs in the fiber duct during the pull-out process. After full debonding, the pull-out process is governed primarily by friction. Therefore, the value of the frictional shear stress has a significant effect on the pull-out work. Figure 6 shows the effect of the damage coefficient $\xi$ on the value of the pull-out work of a steel fiber. It can be observed that for low values of end slip $(0 \cdot 1-0.2$ in) the effect of $\xi$ is small, whereas for larger end slips $(0.8-1.0$ in) the effect of $\xi$ is very important. This is because $\xi$ affects only the frictional stresses, which dominate the pull-out response after debonding. Figure 7 illustrates how the cumulative pull-out work varies with the end slip for various damage coefficients. In the example described, the pull-out work value is more than halved for a damage coefficient varying from 0 to $0 \cdot 9$.

\section{Initial frictional stress}

For a typical bond-slip curve representative of smooth steel fibers in a cementitious matrix, the maximum (or peak) pull-out load $P_{\mathrm{p}}$ increases linearly with the initial frictional shear stress $\tau_{\mathrm{fi}}$ (Fig. 8). The effect of the initial frictional shear stress, $\tau_{\mathrm{fi}}$, on the total pull-out work is illustrated in Fig. 9, where the total pull-out work is com-

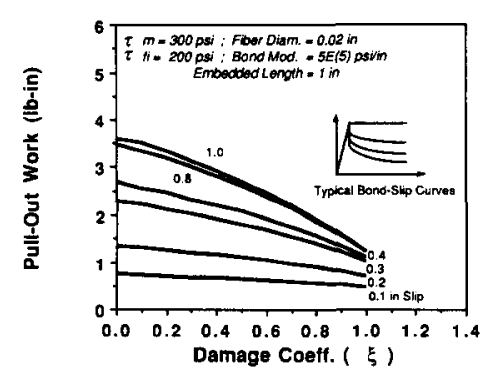

Fig. 6. Typical effect of damage coefficient $\xi$ on the pullout work at various end slips.

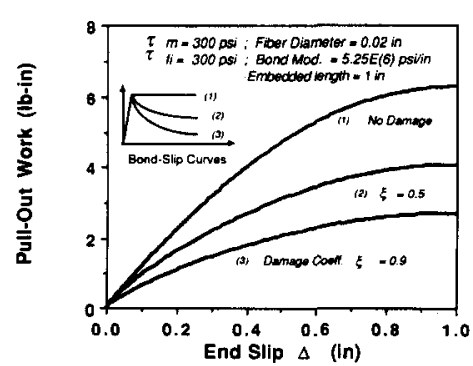

Fig. 7. Pull-out work versus end slip, with constant and decaying friction. puted using a bond-slip model with either a constant friction or a decaying friction. Both models show that the total pull-out work increases with increase in initial frictional shear stress; however, the constant friction model leads to a value of total pull-out work almost five times that given by the decaying friction model.

Figure 10 shows that the debonding pull-out work, for typical bond-slip curves, increases with increase in the initial frictional shear stress $\tau_{\mathrm{fi}}$. The debonding pull-out work is defined as the work of pull-out up to full debonding along the fiber; it does not include the kinematic mechanism of pull-out. It should be noted, in comparing Fig. 10 with Fig. 9, that the numerical value of the total pull-out work can be two to three orders of magnitude larger than the debonding pull-out work. Figure 11 provides a comparison of the debond-

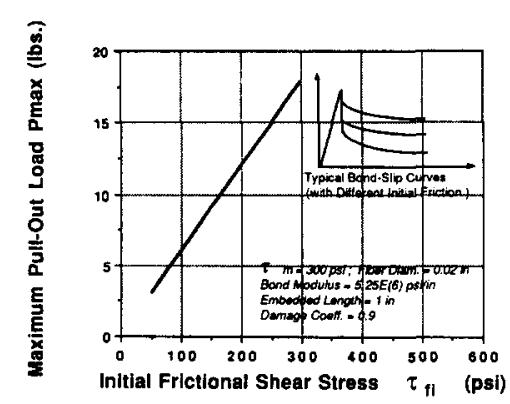

Fig. 8. Effect of initial frictional shear stress $\tau_{\mathrm{fi}}$ on the maximum pull-out load $P_{\max }$.

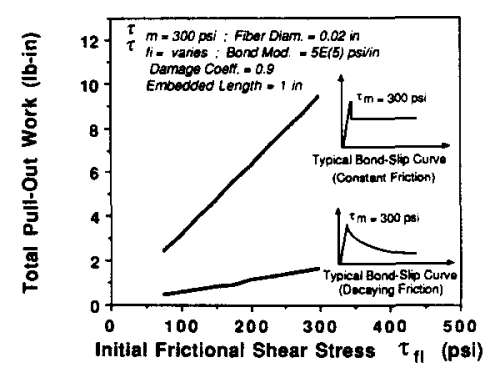

Fig. 9. Typical variation of total pull-out work versus $\tau_{\mathrm{fi}}$ for constant and decaying friction $(1 \mathrm{lb}$ in $=0.113 \mathrm{~N} \mathrm{~m})$.

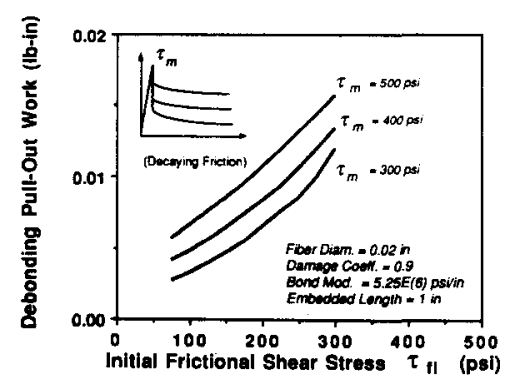

Fig. 10. Effect of initial frictional shear stress $\tau_{\mathrm{fi}}$ on the debonding pull-out work. 
ing pull-out work as computed from the model of this study with a model developed by Brandt in which the initial frictional stress $\tau_{\mathrm{fi}}$ was not considered. Brandt defines the debonding pull-out work as the area under the elastic portion of the bond-slip curve. Because of that, more than $100 \%$ difference in debonding pull-out work can be observed.

\section{Maximum elastic shear stress}

The debonding pull-out work increases significantly with an increase in the maximum bond strength $\tau_{\max }$ (Fig. 12). However, the effect of $\tau_{\max }$ on the total pull-out work is almost negligible (Fig. 13 ), as $\tau_{\max }$ influences only the ascending branch of the pull-out curve. In Fig. 14, the model used in this study to predict debonding pull-out work is compared with the approximate model described

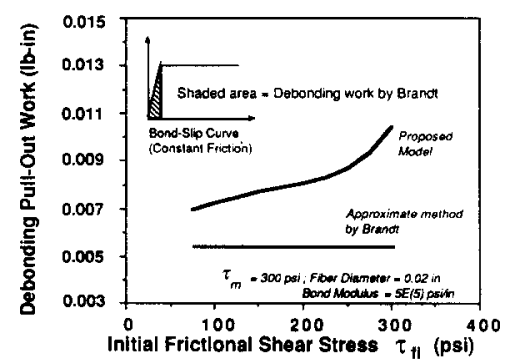

Fig. 11. Comparison of the debonding pull-out work calculated from the present model and Brandt's model for a given initial frictional shear stress $\tau_{\mathrm{fi}}$.

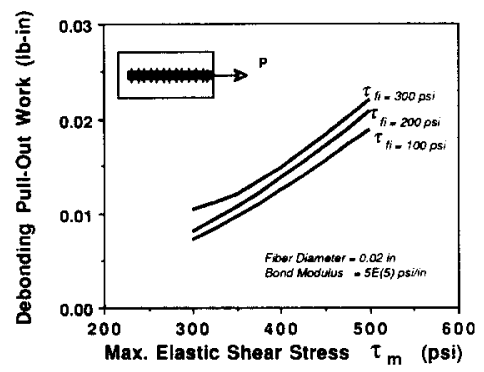

Fig. 12. Effect of maximum elastic bond shear stress $\tau_{\max }$ on the debonding pull-out work.

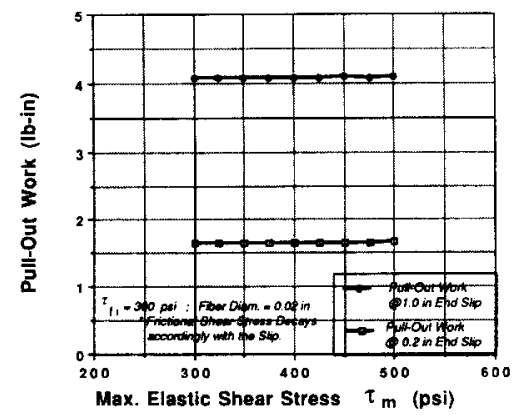

Fig. 13. Effect of maximum elastic bond shear stress $\tau_{\max }$ on the pull-out work at various end slips. in Ref. 2. A difference close to $45 \%$ is observed between the numerical predictions of the two models. Finally, Fig. 15 shows the cumulative pull-out work as a function of the end slip for different bond shear stresses.

\section{Bond modulus}

The effect of the bond modulus $\kappa$ on the pull-out work is limited to the debonding stage, because $\kappa$ affects only the ascending branch of the pull-out load versus slip curve. Moreover, the numerical value of $\kappa$ is relatively large, leading to a small area (work) under the pull-out curve. Hence, for the practically observed range of values of $\kappa$, almost no change is observed in the total pull-out work.

\section{Fiber geometric parameters}

The fiber geometric parameters are mainly the fiber diameter and its embedded length. The two parameters can be combined to lead to one parameter, the aspect ratio $(1 / d)$.

\section{Fiber diameter}

The effect of the fiber diameter on the pull-out work is shown in Fig. 16 for various amounts of end slip. It can be observed that the pull-out work increases linearly with fiber diameter at any slip, whereas, for a given fiber diameter, it also increases with increasing slip.

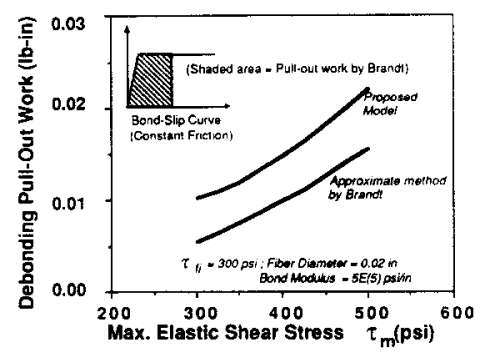

Fig. 14. Comparison of the debonding pull-out work calculated from the present model and Brandt's model for a given maximum elastic bond shear stress $\tau_{\max }$.

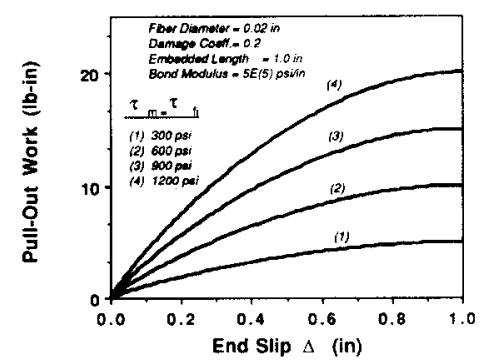

Fig. 15. Typical effect of bond strength on the pull-out work. 


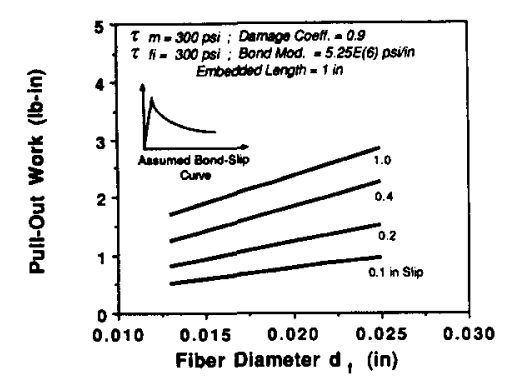

Fig. 16. Effect of fiber diameter on the pull-out work at various end slips.

\section{Fiber embedded length}

The typical pull-out work dependence on the fiber embedded length is illustrated in Fig. 17 for four different damage coefficients. As long as a pull-out mechanism, instead of fiber failure, prevails, the total pull-out work increases more than proportionately with the embedded length. A similar trend is observed for the debonding pullout work, as shown in Fig. 18.

\section{Fiber aspect ratio}

The effect of the two previous parameters (fiber length and diameter) are combined in Fig. 19, in which the total pull-out work is plotted versus the aspect ratio, assuming different fiber diameters. It can be observed that, for a given fiber diameter, the total pull-out work increases more than proportionately with the fiber aspect ratio; a similar observation can be made of the variation of total pull-out work with fiber diameter, for a given aspect ratio.

\section{STRAIN ENERGY RELEASE RATE}

The method of calculating the pull-out work illustrated in this study can be used in conjunction with an appropriate structural model to compute the strain energy release rate $G$ of the fibermatrix interface. The significance of this approach is that a fracture parameter ( $G$ in this case) can be computed from a strength model based on a bond-slip relationship (pull-out work). Assuming the pull-out model shown in Fig. 1, the energy released, $R$, for an increase, $\mathrm{d} u$, in the debonded length, $u$, can be expressed as

$$
R=P . \mathrm{d} \Delta-\mathrm{d} W_{\mathrm{sf}}-\mathrm{d} W_{\mathrm{sm}}-\mathrm{d} W_{\mathrm{sfm}}-\mathrm{d} W_{\mathrm{f}}
$$

where $P . \mathrm{d} \Delta$ is the pull-out work computed from the model presented above and corresponding to a strip area under the $P-\Delta$ curve; $\mathrm{d} W_{\mathrm{sf}}$ is the strain energy in the debonded portion of the fiber, which

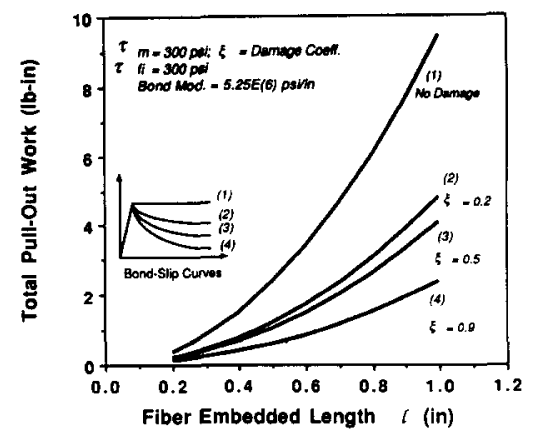

Fig. 17. Effect of fiber embedded length on the total pullout work.

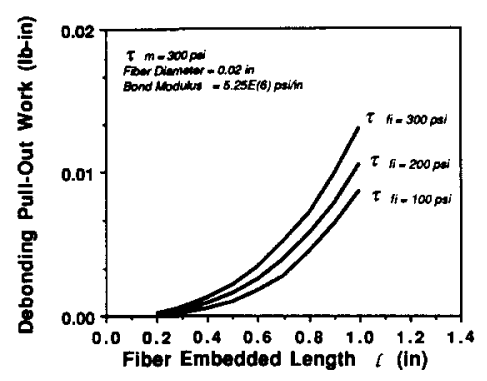

Fig. 18. Effect of fiber embedded length on the debonding pull-out work.

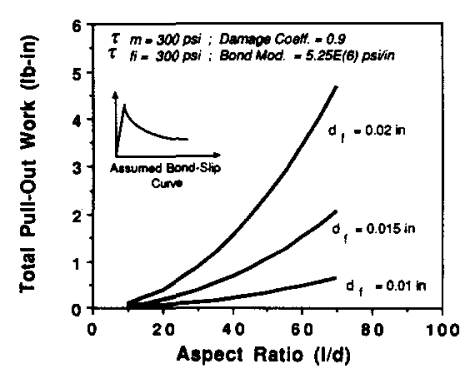

Fig. 19. Effect of the fiber aspect ratio on the total pull-out work.

is equal to $\mathrm{d} W_{\mathrm{sm}}$ the strain energy in the debonded portion of the matrix; $\mathrm{d} W_{\mathrm{sfm}}$ is the strain energy in the bonded portion of the fiber-matrix system; and $\mathrm{d} W_{\mathrm{f}}$ is the work done by friction along the debonded portion of the fiber. For simplicity, one can define $\mathrm{d} W_{\mathrm{s}}$ to be the summation of the strain energy in the described system.

Differentiating eqn (7) with respect to the debonded length $u$ (which represents the crack length in a fracture analysis), leads to

$$
G_{\mathrm{c}}=P \cdot \frac{\mathrm{d} \Delta}{\mathrm{d} u}-\frac{\mathrm{d} W_{\mathrm{s}}}{\mathrm{d} u}-\frac{\mathrm{d} W_{\mathrm{f}}}{\mathrm{d} u}
$$

where $G_{\mathrm{c}}$ is the critical strain energy release rate at which debonding occurs. A mathematical solution could be obtained from the equations presented in Ref. 9 to develop expressions for 
$\mathrm{d} W_{\mathrm{s}} / \mathrm{d} u$ and $\mathrm{d} W_{\mathrm{f}} / \mathrm{d} u$. Moreover, the $P(\mathrm{~d} \Delta / \mathrm{d} u)$ term can be evaluated directly from the model presented here. Thus, an estimate of the critical strain energy release rate, $G_{\mathrm{c}}$, can be obtained.

An equation similar to eqn (8) was used by Stang et al.; their objective was to predict the pull-out load versus end displacement $(P-\Delta)$ curve, based on a fracture mechanics approach. However, in their approach, the strain energy release rate, $G$, was considered an interface property; debonding occurred when the energy release rate reached a critical value related to the work of fracture of the interface, $\Gamma$. The work of fracture, $\Gamma$ (or $G_{\mathrm{c}}$ ) is assumed a given parameter. The other terms in eqn (8), namely, the work of friction and the strain energy in various parts of the system, were computed based on a structural model which assumes a unit cell of composite made out of a cylindrical matrix with a single embedded fiber. The matrix cylinder was modeled as a shear lag with shear stiffness $k$, and having fixed end boundaries. As the model developed in this study allows for the direct determination of the $P(\mathrm{~d} \Delta / \mathrm{d} u)$ term, there is no need to assume a value of the critical strain energy release rate, $G_{c}$. It could be obtained directly fom solving eqn $(8)$.

\section{CONCLUSIONS}

An analytical model for the pull-out problem based on a realistic bond shear stress versus slip relationship was used to compute the pull-out work of steel fibers from cementitious matrices. The main conclusions of the analysis are summarized below.

(1) Two bond-slip parameters were observed to affect the total pull-out work (i.e. work to complete pull-out) more than others; namely, the initial frictional bond shear stress, $\tau_{\mathrm{fi}}$, and the damage coefficient, $\xi$, which describes the extent of decay in frictional resistance at large slips. On the other hand, the debonding pull-out work (i.e. the work up to full debonding along the fiber-matrix interface) was influenced by the value of the maximum elastic bond shear stress, $\tau_{\max }$, as well as the initial frictional bond shear stress, $\tau_{\mathrm{fi}}$.

(2) In determining the numerical value of the debonding pull-out work, the proposed model suggests that the influence of the initial frictional shear stress cannot be neglected. Indeed, its inclusion in the analysis leads to more than doubling of the debonding pull-out work predicted otherwise.

(3) The work to complete pull-out for a typical smooth steel fiber with 1 in $(25 \mathrm{~mm})$ embedded length was two to three orders of magnitude larger than the pull-out work to complete debonding. This stresses the importance of the frictional work of pullout in the toughness and energy absorption capability of fiber reinforced cementitious and ceramic composites.

(4) The damage coefficient, $\xi$, which characterizes frictional decay during pull-out, influences the pull-out work significantly more at large slips than at small slips. This may be important in practical design where other criteria such as crack widths and deflections may become critical before large slips develop.

(5) For a given fiber diameter, the total pull-out work increases more than proportionately with the fiber aspect ratio. This implies that, provided a pull-out mechanism can be maintained instead of fiber failure, and everything else is kept the same, more than a direct gain in toughness can be achieved by increasing the fiber aspect ratio.

The model described here to evaluate the pullout work could be used to determine the critical strain energy release rate, $G_{\mathrm{c}}$, of the fiber-matrix interface, thus providing a transformation tool by which a fracture parameter, $G_{c}$, is computed from a strength-based model. However, further investigation is needed to expand this approach in more detail.

\section{ACKNOWLEDGEMENT}

This research was supported in part by a grant from the National Science Foundation to the NSF Center for Advanced Cement Based Materials. The Center is a consortium of five institutions: Northwestern University, University of Illinois at Urbana-Champaign, University of Michigan, Purdue University, and the National Institute of Standards and Technology. Any opinions, findings and conclusions expressed in this study are those of the authors and do not necessarily reflect the views of NSF or the ACBM Center. 


\section{REFERENCES}

1. Becher, P., Crack bridging process in toughened ceramics. NATO Advanced Research Workshop, Toughening Mechanisms in Quasi-Brittle Materials, Workshop Proceedings, 16-20 July 1990, pp. 19-37.

2. Brandt, A. M., On the optimal direction of short metal fibers in brittle matrix composites. J. Mat. Sci., 20 (1985) 3831-41.

3. Currie, B. \& Gardiner, T., Bond between polypropylene fibers and cement matrix. Int. J. Cement Composites and Lightweight Concrete, 11 (1989) 3-9.

4. Helfet, J. L. \& Harris, B., Fracture toughness of composites reinforced with discontinuous fibers. J. Mat. Sci. 7 (1972) 494-8.

5. Kelly, A., Interface effects and the work of fracture of a fibrous composite. Proc. Roy. Soc. Lond., A319 (1970) 95.

6. Leung, C. K. \& Li, V. C., A new strength-based model for the debonding of discontinuous fibers in an elastic matrix. Report UMCE 90-17, Dept. of Civil Enging, University of Michigan, Ann Arbor, 1990.

7. Mandel, J., Wei, S. \& Said, S., Studies of the properties of the fiber-matrix interface in steel fiber reinforced mortar. ACI Materials J., 84 (1987) 101-9.
8. Naaman, A. E. \& Najm, H., Bond-slip mechanisms of steel fibers in concrete. ACI Materials J., 88 (1991) 135-45.

9. Naaman, A. E., Namur, G., Alwan, J. M. \& Najm, H., Fiber Pullout and Bond Slip. I: Analytical Study; II: Experimental Validation, ASCE J. of Structural Engineering, 117 (1991) 2769-800.

10. Namur, G., Naaman, A. E. \& Clark, S. K., Analytical prediction of pull-out behavior of steel fibers in cementitious matrices. Mat. Res. Soc., Symp. Proc., 114 (1988) 217-24.

11. Outwater, J. O. \& Murphy, M. C., The fracture energy of unidirectional laminates. Proc. 24th Annual Technical Conference, Society of the Plastic Industry, 1969.

12. Stang, H., Li, Z. \& Shah, S. P., Pull-out problem: stress versus fracture mechanical approach. ASCE J. Eng. Mech., 116 (1990) 2136-50.

13. Stang, H. \& Shah, S. P., Failure of fiber-reinforced composites by pull-out fracture. J. Mat. Sci., 21 (1986) 953-7.

14. Wang, Y., Li, V. C. \& Backer, S., Modelling of fiber pullout from a cement matrix. Int. J. Cement Composites and Lightweight Concrete, 10 (1988) 143-9.

15. Wei, S., Mandel, J. \& Said, S., Study of the interface strength in steel fiber-reinforced cement based composites. ACI Materials J., 83 (1986) 597-605. 